\title{
Postnatal Care Service Utilization and Associated Factor Among Reproductive Age Women Who Live in Dolo Addo District, Somali Region, Southeast Ethiopia
}

\author{
Abdurahman Kedir Roble ${ }^{1}$, Ahmed Mohammed Ibrahim², Mohamed Omar Osman², \\ Girma Tadesse Wedajo ${ }^{2}$, Abduselam Usman Absiye ${ }^{3}$, Rahima Olad Hudle ${ }^{3}$ \\ ${ }^{1}$ Department of Midwifery, College of Medicine and Health Science, Jigjiga University, Jigjiga, Ethiopia \\ ${ }^{2}$ Department of Public Health, College of Medicine and Health Science, Jigjiga University, Jigjiga, Ethiopia \\ ${ }^{3}$ Department of Obstetrics and Gynecology Sheikh Hassen Yebere Referral Hospital, Jigjiga University, Jigjiga, Ethiopia
}

Email address:

kedirabdurahman114@gmail.com (A. K. Roble),Ahmey114baba@gmail.com (A. M. Ibrahim),

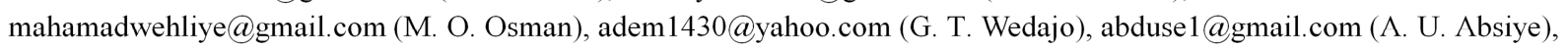

rahimaolad@gmail.com (R. O. Hudle)

\section{To cite this article:}

Abdurahman Kedir Roble, Ahmed Mohammed Ibrahim, Mohamed Omar Osman, Girma Tadesse Wedajo, Abduselam Usman Absiye, Rahima Olad Hudle. Postnatal Care Service Utilization and Associated Factor Among Reproductive Age Women Who Live in Dolo Addo District, Somali Region, Southeast Ethiopia. European Journal of Preventive Medicine. Vol. 8, No. 3, 2020, pp. 24-29.

doi: 10.11648/j.ejpm.20200803.11

Received: March 29, 2020; Accepted: April 17, 2020; Published: April 29, 2020

\begin{abstract}
The Postnatal period is a critical time for both mothers and her baby. A care given during this period is reduce a numerous of maternal and neonatal death. Despite its importance of Postnatal care utilization, little is known about this postnatal care utilization and associated factors in this study area, so this study aimed to assess postnatal care services utilization and associated factors among reproductive women who gave live birth in last two years in Dolo Addo District Somali region southeastern Ethiopia. A community-based cross-sectional study was conducted among 388 women who gave live birth during last two years prior to the study. Data was collected by using structured questionnaire. Bivariate and multivariable logistic regression analyses was done. During multivariate analysis a variable with p-value less than 0.05 declared significantly associated with Postnatal care service utilization. This study reported that prevalence of postnatal utilization is $22.2 \%$ among reproductive age women in Dolo Addo district. Factor associated with PNC included, having ANC visit during pregnancy $(\mathrm{AOR}=3.03,95 \% \mathrm{CI}=1.74,5.29)$, and place of delivery $(\mathrm{AOR}=2.23,95 \% \mathrm{CI}=1.25,3.98)$ and maternal health care decision power $(\mathrm{AOR}=1.78,95 \% \mathrm{CI}=1.05,3.01)$ were a factors significantly associated with postnatal care service utilization. In this study nearly quarter of the women utilize PNC in Dolo Addo District. In order to enhance PNC in this area intervention should be targeted during ANC follow up, during labor and delivery. Furthermore, crucial steps should be taken to empower women which improve utilization of maternal health care service.
\end{abstract}

Keywords: Postnatal Care, Factor Associated, Dolo Addo

\section{Background}

The postnatal period is period of first six weeks following child birth and it special phase in the life of a woman and her newborn [1]. Postnatal care (PNC) one of basic maternal and newborn care designed to all women and baby during the first 42 days after the child birth [2]. According to World Health organization all mothers and newborns should receive as initial PNC care within the first 24 hours and other three extra PNC within 48-72 hours, 7-14 days, and at 6 weeks after delivery without considering place of delivery [3].

Despite Sustainable Development Goal (SDG) plan to reduce MMR less than 70 per 100,000, every day 810 global women die due to direct and indirect obstetric cause. Globally about 295,000 women died every year due to complications that occur during pregnancy, childbirth and postnatal period. Nearly $94 \%$ of maternal death occurred in low-resource settings and most might be prevented using 
different intervention like postnatal care [4].

Essential postnatal care (PNC) package include assessment mothers and baby for any complication like bleeding, infection, depression, counseling on danger sign, family planning, breastfeeding, nutrition and hygiene in order to prevent disease and promote maternal and child health $[5,6]$.

Report from UNICEF indicated that an estimated 2.5 million children died in their first month of life during 2018 from preventable causes, more than 2 million neonate died during the first week with approximately one million dying in their first day of postnatal period [7]. In other hand an estimated $50 \%$ to $71 \%$ of maternal death is occur in the postnatal period where as $45 \%$ of postpartum maternal deaths occur during the first 24 hours, and more than $70 \%$ of maternal deaths happen during the first weeks of postnatal period [8]. Severe obstetric bleeding and sepsis are major cause of death in developing countries that happened during postnatal period. Furthermore, Postpartum bleeding can kill even a healthy woman within two hours if not treated [9]. Most of this death could be easily prevented with simple, cost effective intervention following birth [10].

Preventive care provide during postnatal period could have the greatest impact on maternal, fetal and newborn survival. It also reported that countries with low utilization of postnatal care were more associated with high neonatal and maternal death [11]. Despite the benefits of PNC services, postnatal period is generally neglected in developing countries where most of mothers and babies do not receive postnatal care services from a skilled health care provider during the first few days after delivery [12].

Proper PNC utilization to avert and treat complications during this critical period is likely to have a significant impact on reducing maternal deaths, and early neonatal deaths however PNC still one of most forgotten area of maternal health in sub-Sahara Africa [13, 14].

In Ethiopia evidence from different study show that less than half of the women receive postnatal care from skilled health professionals. Utilization of postnatal service is one of key measurement in reducing maternal and infant death. However, in Ethiopia postnatal care remains a challenge and needs more attention. In Somali region only 10 of women attend postnatal care utilization [15].

\section{Method and Material}

\subsection{Study Setting and Period}

The study was conducted in Dolo Addo district, one of the woreda of Somali regional state, south Eastern Ethiopia. The district is one of the 7 districts of Liban zone. It is located at $950 \mathrm{~km}$ distances from the capital City of Addis Ababa and border with somalia and Kenya. The District is found the angle formed by confluece of the the Genele with Dawa rever. Acording to 2007 national census reported a total population of this district were 111,511 , of whom 60,778 are men and 50,733 are women; 37,404 or $33.54 \%$ of its population are urban dwellers whereas $33869(30.37 \%)$ of total population are pastoralist. There are four refugee camp found in the woreda. The main economic source in this area are trade, agriculture and livestock [16]. This study was conducted from September to October 2019 among reproductive age women who gave birth within last two years preceding this study.

\subsection{Study Design}

Community based cross sectional study was used among reproductive age women who gave live birth in past 24 months preceding the study in Dolo Addo District.

\subsection{Study Population}

Study populations were randomly selected women who gave birth in last 24 Months preceding the study. Those women who delivered live child birth two years before data collection and live at least 6 months in selected Keble's were included in the study. Those mothers who were seriously ill and unable to respond during data collection were excluded from the study.

\subsection{Sample Size Determination}

The minimum required sample size of this study was determined using single population proportion formula. Proportion of postnatal care service utilization taking from study done in Debretabour 57.5\% [17].

$$
\mathrm{n}=\frac{(\mathrm{Z} \alpha / 2)^{2} \mathrm{p}(1-\mathrm{p})}{(\mathrm{d})^{2}}
$$

Where $\mathrm{n}=$ Sample size, $\mathrm{Z}=$ value corresponding to a $95 \%$ level of significance $=1.96$

$\mathrm{P}=$ proportion of $\mathrm{PNC}$ service utilization 57.5\%

$\mathrm{d}=$ marginal error assumed to be $5 \%$

$$
\begin{gathered}
(1-\mathrm{p})=(1-0.575)=0.425 \\
\mathrm{n}=\frac{(1.96)^{2}(0.575 \times 0.425)}{(0.05)^{2}}=376
\end{gathered}
$$

By adding $5 \%$ of non-response rate the total sample size for this study was 395 .

\subsection{Sampling Technique and Procedures}

From 24 kebele of Dolo Addo District 9 kebeles were selected using simple random sampling techniques. Then the calculated sample sizes of 395 were proportionally allocated to the each selected kebeles. The total Household with mother who gave birth in last 24 months were taken from each kebele administration then sampling frame was prepared, lastly using systematic sampling house hold with eligible women was visited. The first house hold was selected using lottery method. If no eligible person in the selected household the next household was visited accordingly.

\subsection{Data Collection Method}

The data was collected using structured and pretested 
interviewer administered questionnaires which initially prepared in English and then translate into Somali language then back into English to check for any inconsistencies or distortion. Data were collected by seven diploma midwives and three 3 BSc supervisors.

\subsection{Data Quality Control}

Data quality was assured through training of data collectors and pretesting questionnaire in community similar to the study population then possible modification was made before the actual data collection. The collected data were checked for completeness and consistency throughout data collection and processing, furthermore closely supervision was made during data collection period.

\subsection{Data Processing and Analysis}

The collected data were checked visually by the principal investigators. Then data were coded and entered using Epidata version 4.2. Then Exported to SPSS version 22 for processing and analysis. Descriptive statistics of different variables was done by using tables and figures. Binary logistic regression models using bivariate [crude odds ratio, [COR] and multivariable analysis [adjusted odds ratio, AOR] with 95\% Confidence interval [CI] was used. During bivariate analysis variable with $\mathrm{p}<0.25$ was further included in multivariate analysis. During multivariate analysis, variable with $\mathrm{p}<0.05$ was considered as statistically significant and independently associated with postnatal care utilization.

\subsection{Ethical Clearance}

The study was conducted after getting ethical clearance from Jigjiga University, College of Medicine and Health Science, Institution of Health Research Review committee. In addition, written informed consent was obtained from each study participant to confirm willingness for participation after explaining the objective of the study.

\section{Results}

\subsection{Socio Demographic Characteristics}

A total of 388 study participants were included in this study with response rate of $98.2 \%$. The mean age of the participants was 26.8 years $(\mathrm{SD} \pm 6.2)$ and more than one third (39.7\%) of women were in the age range of 26-30 years. Majority of them (93.4\%) were married and Somali (94.6\%). More than two third of the women were not attended formal education and only $56(14.4 \%)$ attended college and university. Detail in Table 1.

Table 1. Sociodemographic characteristic of Respondents in Dolo Addo District Somali Region, Southeastern Ethiopia 2019.

\begin{tabular}{|c|c|c|c|}
\hline Characteristics & Categories & Frequency $(n=388)$ & Percent \\
\hline \multirow{4}{*}{ Age } & $<19$ & 26 & 6.7 \\
\hline & $19-25$ & 154 & 39.7 \\
\hline & $26-30$ & 123 & 31.7 \\
\hline & $>30$ & 85 & 21.9 \\
\hline \multirow{2}{*}{ Marital status } & Married & 362 & 93.3 \\
\hline & Divorced and widowed & 26 & 6.7 \\
\hline Ethnicity & Others (Amahara, and oromo) & 21 & 5.4 \\
\hline \multirow{2}{*}{ Religion } & Muslim. & 377 & 97.2 \\
\hline & Others (orthodox and protestant) & 11 & 2.8 \\
\hline \multirow{4}{*}{ Educational level of the mother } & No formal education & 136 & 35 \\
\hline & Primary $(1-8)$ & 124 & 32 \\
\hline & Secondary $(9-12)$ & 72 & 18.6 \\
\hline & College or University & 56 & 14.4 \\
\hline \multirow{2}{*}{ Occupational status of mother } & Paid salary & 142 & 36.6 \\
\hline & Not Paid salary & 246 & 63.4 \\
\hline \multirow{2}{*}{ Time taken to reach health facility } & $<$ One Hrs & 174 & 44.8 \\
\hline & More than one Hrs. & 214 & 55.8 \\
\hline
\end{tabular}

\subsection{Obstetric and Child Health Related Characteristics of the Respondents}

Among the total of 388 study participants included in the study, two hundred-ninety-eight $(76.2 \%)$ were multipara and where as $23.8 \%$ were Prim Para. From all participant only eighty-four $(23.8 \%)$ women attend at least one ANC visit during their last pregnancy. Regarding place of child birth, majority $(79.4 \%)$ of the women give birth at home, only
$20.6 \%$ of the women delivered last baby in Health institution. About $160(41.2 \%)$ women reported that they are autonomous to receive maternal health care service and more than half of women reported that, they are not autonomous to receive maternal health care. In other hand 116 women (29.9) women have complication during postnatal period while the rest were not. From all respondents, 72 (18.6\%) women reported that at least one episode of illness occurred in their child during postnatal period. 
Table 2. Distrbution of Obstetrics and child related chracterstics of Respondents in Dolo Addo District, Somali Region, Southeastern Ethiopia 2019.

\begin{tabular}{llll}
\hline Characteristics & Categories & Frequency & Percent \\
\hline \multirow{2}{*}{ Parity } & prim-parity & 90 & 23.8 \\
& Multipara & 298 & 76.2 \\
Ever Attend ANC in Previous Pregnancy (n=) & Yes & 84 & 21.6 \\
& No & 304 & 78.4 \\
Number of previous 1 $1^{\text {st }}$ ANC visit (n=86) & $<$ less than 3 visit & 54 & 64.3 \\
Place of Delivery & 3 and 4 visits & 30 & 35.7 \\
& Institution & 80 & 20.6 \\
Mode of delivery & Home & 308 & 79.4 \\
Any complication during postnatal period & Normal SVD & 351 & 90.5 \\
& Operative delivery & 37 & 9.5 \\
Maternal care decision autonomy & Yes & 116 & 29.9 \\
Child sick during postnatal period & No & 272 & 70.1 \\
& Autonomous & 160 & 41.2 \\
\hline
\end{tabular}

\subsection{Prevalence of Postnatal Care Utilization}

The prevalence of Postnatal care service utilization among the respondents was $22.2 \%(95 \% \mathrm{CI}=17.5,26.1)$, that means 86 women uses at least one PNC service while the rest 302 women not utilize PNC during the period of first six weeks. Nearly one-third of PNC utilizer were receiving PNC care at first week and about 45 percent of participants attend $\mathrm{PNC}$ at second weeks. At third week 6 and 13 (15.1) women were received PNC during third weeks and more than fourth to six weeks

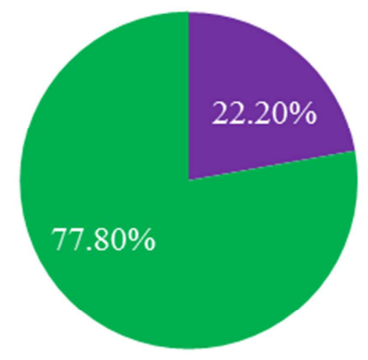

घNC utilization $\quad$ Not utilize PNC

Figure 1. Prevalence of Postnatal care service Utilization among women of Reproductive age in Dolo Addo District 2019.

\subsection{Reason for Not Utilizing PNC}

In this study, $77.8 \%$ women not attend PNC. Being health (42.4\%), not have knowledge of PNC (35.1\%), no transport $(8.3 \%)$, busy with work $(8.6 \%)$, Long distance to Health facilities $(5.6 \%)$, were reasons mentioned for not receiving PNC during the first six weeks after child birth.

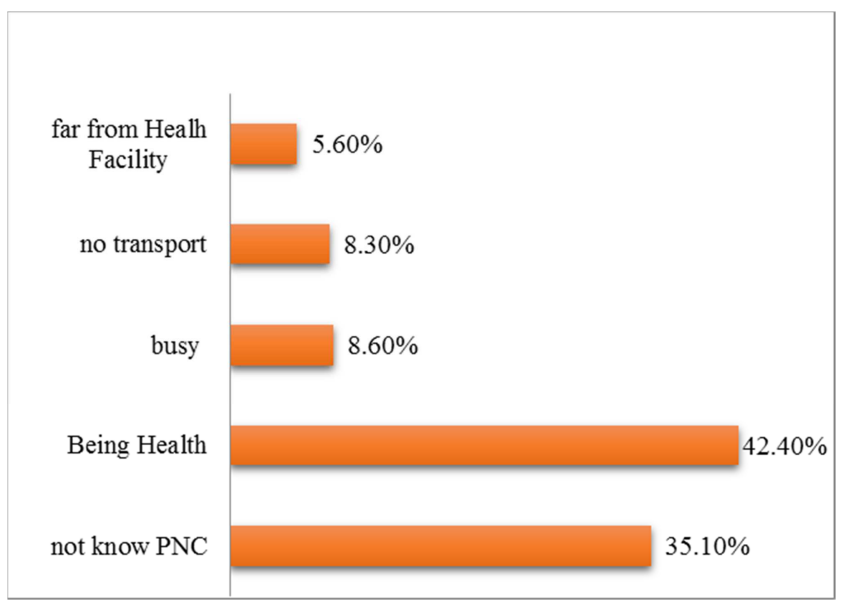

Figure 2. Reason for not utilizing PNC among women of Reproductive age in Dolo Addo District, Somali Region Southeastern Ethiopia 2019.

\subsection{Factor Associated with Postnatal Care}

Occupation of the women, time to reach health facility, parity of the women, ANC utilization during pregnancy, place of last baby delivery, child illness during postnatal period and maternal care power were among variable included in multivariate analysis. In multivariate analysis, ANC utilization during pregnancy, Place of last baby delivery, and maternal care decision power were among variable which show significant association with Postnatal care utilization.

Mothers who were followed ANC during their pregnancy time were 3 times higher [AOR 3.03, 95\% CI $(1.74,5.29)$ ] to utilize PNC comparing with those not follow ANC during their pregnant time. Place of delivery were also among variable show association with PNC utilization, more specifically those mother who delivered their baby in health institution were significantly associated with [AOR 2.23 , 95\% CI $(1.25,3.98)$ PNC utilization comparing with 
those delivered in Home. The odds of PNC utilization were 1.78 higher [AOR 1.78, 95\% CI 1.05, 3.01)] among women who had autonomous to receive maternal care service comparing with women who were not autonomous.

Table 3. Factor Associated with PNC Utilization among women of Reproductive age in Dolo Addo District, Somali Region, Southeastern Ethiopia 2019.

\begin{tabular}{|c|c|c|c|c|c|}
\hline \multirow{3}{*}{$\begin{array}{l}\text { Variables } \\
\text { Occupation }\end{array}$} & \multirow{2}{*}{$\begin{array}{l}\text { Categories } \\
\text { Paid salary }\end{array}$} & \multicolumn{2}{|c|}{ PNC Utilization Yes (\%) No (\%) } & \multirow{2}{*}{$\begin{array}{l}\text { COR (CI=95\%) } \\
1.60(0.98-2.61)\end{array}$} & \multirow{2}{*}{$\begin{array}{l}\text { AOR }(\mathbf{C I}=\mathbf{9 5 \%}) \\
1.61(0.96,2.73)\end{array}$} \\
\hline & & $39(27.5)$ & $103(72.5)$ & & \\
\hline & Not paid salary & $47(19.1)$ & $199(80.9)$ & 1 & 1 \\
\hline \multirow{2}{*}{ Time to reach health facilities } & $\leq 1 \mathrm{Hr}$ & $46(26.4)$ & $128(73.6)$ & $1.56(0.97-2.5)$ & $1.41(0.84,2.37)$ \\
\hline & $>1 \mathrm{Hrs}$ & $40(18.7)$ & $174(81.3)$ & 1 & 1 \\
\hline \multirow{2}{*}{ Parity } & Primipara & $24(26.7)$ & $66(73.3)$ & $1.38(0.83-2.39)$ & $1.62(0.89,2.91)$ \\
\hline & Multipara & $62(20.8)$ & $236(79.2)$ & 1 & 1 \\
\hline Utilized ANC & No & $51(16.8)$ & $258(83.2)$ & 1 & 1 \\
\hline \multirow{2}{*}{ Place of delivery } & Institution & $30(37.5)$ & $50(62.5)$ & $2.7(1.58-4.62)$ & $2.23(1.25,3.98)^{* *}$ \\
\hline & Home & $56(18.2)$ & $252(81.2)$ & 1 & 1 \\
\hline \multirow{2}{*}{ Child sick during PNC } & Yes & $24(33.3)$ & $48(66.7)$ & $2,05(1.17-3.60)$ & $0.63(0.34,1.16)$ \\
\hline & No & $62(19.6)$ & $254(80.4)$ & 1 & 1 \\
\hline \multirow{2}{*}{ Maternal care Decision } & Autonomous & $43(26.9)$ & $117(73.1)$ & $1.58(0.98,2.56)$ & $1.78(1.05,3.01)^{*}$ \\
\hline & Not autonomous & 43 (18.9) & $185(81.1)$ & 1 & 1 \\
\hline
\end{tabular}

\section{Discussion}

In this study with aim of assesse the prevalence of PNC utilization association factors among mothers in Dolo Addo district of Ethiopia show that the prevalence of PNC service utilization was $22.2 \%$. This study is much higher than study done in Tigray $8 \%$ and study done from EDHS 5.3\% [18, 19]. This might be due to time of the study and number of sample size used. In other hand this finding is lower than finding done in Halaba Kulito Town, Southern Ethiopia which was $47.9 \%$ and Debre Birhan 83.3\% [20, 21]. The possible justification for this discrepancy might be due to the difference in sociodemographic feature of the study participants. Moreover, health service accessibility and exposure to information regarding PNC services different because the current study participants were from remote and peripheral part of Ethiopia.

Antenatal care utilization was found to be associated with PNC utilization. Mothers utilized ANC during their pregnant time were more likely utilize PNC than mother who not visited ANC. Similar finding also reported from study done study in done in Malawi Abuna Gindeberet District of West Shewa, Benchi-Maji Zone, Ethiopia [22-24]. This can be justified that information provided during ANC influence PNC service utilization.

According to this study institutional delivery of the last baby is strong predictors of postnatal care utilization. Those mother who gave birth last baby in health institution were more likely utilize PNC comparing to those delivered in the home, similar finding reported from study done in in lemo District, Loma woreda SNNP of Ethiopia, [25, 26]. This is because Health education and appointment given for women after delivery might enhance decision of women to utilize PNC during postnatal period.

Maternal health decision power has been associated with PNC utilization. those mother had been decision power to receive Health care service were significantly associated with PNC service utilization. This in line with finding reported from India, Nepal, Aseko District of Arsi, Zone of Ethiopia
[27-29]. This may be due to the fact that women equality often influences the women to participate in all aspects including utilizing health care services, education, politics and economic resources.

\section{Conclusion and Recommendation}

The current study found nearly one-fourth of women utilize Postnatal care service during postnatal period in Dolo Addo district of Somali region and it is very low comparing with study done in different parts of Ethiopia. Utilizing ANC, Place of Delivery and Decision making power regarding maternal Health care utilization were among factors associated with postnatal care utilization in Dolo Addo district. The concerned body should be take necessary action in order to enhance maternal health care service. Health care providers should counsel importance and danger condition during this time, giving appointments of PNC utilization at community level, during ANC visit and following child birth should have enhanced. Further more women empowerments should be encouraged as it improves decision power regarding to maternal health care utilization.

\section{Abbreviation}

ANC Antenatal Care, PNC Postnatal Care, WHO World Health Organization.

\section{Competing of Interest}

The authors declare that they have no competing of interest.

\section{Acknowledgements}

We would like to acknowledge the Jigjiga University college of Medicine and Health science for approval of ethical clearance and financial support. 


\section{References}

[1] WHO. Pregnancy child birth postpartum and newborn care guide for essential practice. 2015; Available from: https://www.who.int/maternal_child_adolescent/documents/im ca-essential-practical-guide/en/.

[2] WHO. WHO Technical Consultation on Postpartum and Postnatal Care. 2010; Available from: https://apps.who.int/iris/bitstream/handle/10665/70432/WHO MPS_10.03_eng.pdf;jsessionid=7A1354DD8E349E9A0AF2 A4E566234A 51 ? sequence $=1$.

[3] WHO, WHO recommendations on newborn health: guidelines approved by the WHO Guidelines Review Committee, 2017, World Health Organization.

[4] WHO. Maternal mortality. 2019 [cited 2020 March 9].

[5] ACOG, ACOG Committee Opinion No. 736: Optimizing Postpartum Care. Obstetrics and gynecology, 2018. 131 (5): p. e140-e150.

[6] UNCEF. Pregnancy, Childbirth, Postpartum and Newborn Care: A guide for essential practice. 2015 [cited 2020 March 9]; Available from: https://data.unicef.org/resources/pregnancy-childbirthpostpartum-newborn-care-guide-essential-practice/.

[7] UNICEF. The first month of life is the most vulnerable period. 2019 [cited 20209 March]; Available from: https://data.unicef.org/topic/maternal-health/newborn-care/.

[8] WHO. The world health report, make every mother and child count. 2005 [cited 20209 March]; Available from: https://www.who.int/whr/2005/chapter4/en/index1.html.

[9] Bailey, P. E., et al., The triple threat of pregnancy, HIV infection and malaria: reported causes of maternal mortality in two nationwide health facility assessments in Mozambique, 2007 and 2012. BMC pregnancy and childbirth, 2015. 15: p. 293-293.

[10] WHO. Postnatal Care for Mothers and Newborns Highlights from the World Health Organization 2013 Guidelines 2015 [cited $2020 \quad 9$ March]; Available from: https://www.who.int/maternal_child_adolescent/publications/ WHO-MCA-PNC-2014-Briefer_A4.pdf.

[11] WHO. Newborns: reducing mortality. 2019 [cited 20209 , March]; Available from: https://www.who.int/news-room/factsheets/detail/newborns-reducing-mortality.

[12] WHO. WHO Recommendations on Postnatal Care of the Mother and Newborn - 2013. 2013 [cited 2020 March, 9]; Available https:/www.healthynewbornnetwork.org/resource/whorecommendations-on-postnatal-care-of-the-mother-andnewborn-2013/.

[13] Singh, K., P. Brodish, and E. Haney, Postnatal care by provider type and neonatal death in sub-Saharan Africa: a multilevel analysis. BMC Public Health, 2014. 14 (1): p. 941.

[14] Carvajal-Aguirre, L., et al., Gap between contact and content in maternal and newborn care: An analysis of data from 20 countries in sub-Saharan Africa. Journal of global health, 2017. 7 (2): p. 020501-020501.
[15] EPHI. Mini Demographic and Health Survey Key Indicators, 2019. 2019 [cited 2020 March, 9]; Available from: https://www.ephi.gov.et/images/files/Excutive-summary--mini-DHS-2019_Final-1.pdf.

[16] Wikipedia. Dolo Odo, Somali Region, Ethiopia. 2019; Available from: https://en.wikipedia.org/wiki/Dolo_Odo.

[17] Wudineh, K. G., et al., Postnatal care service utilization and associated factors among women who gave birth in Debretabour town, North West Ethiopia: a community- based cross-sectional study. BMC Pregnancy Childbirth, 2018. 18 (1): p. 508.

[18] Berhe, A., et al., Determinants of postnatal care utilization in Tigray, Northern Ethiopia: A community based cross-sectional study. PLoS One, 2019. 14 (8): p. e0221161.

[19] Ayele, B. G., et al., Magnitude and determinants for place of postnatal care utilization among mothers who delivered at home in Ethiopia: a multinomial analysis from the 2016 Ethiopian demographic health survey. Reprod Health, 2019. $16(1)$ : p. 162.

[20] Abuka Abebo, T. and D. Jember Tesfaye, Postnatal care utilization and associated factors among women of reproductive age Group in Halaba Kulito Town, Southern Ethiopia. Arch Public Health, 2018. 76: p. 9.

[21] Angore, B. N., E. G. Tufa, and F. S. Bisetegen, Determinants of postnatal care utilization in urban community among women in Debre Birhan Town, Northern Shewa, Ethiopia. J Health Popul Nutr, 2018.37 (1): p. 10.

[22] Khaki, J. J. and L. Sithole, Factors associated with the utilization of postnatal care services among Malawian women. Malawi medical journal: the journal of Medical Association of Malawi, 2019. 31 (1): p. 2-11.

[23] Darega, B., et al., Institutional delivery and postnatal care services utilizations in Abuna Gindeberet District, West Shewa, Oromiya Region, Central Ethiopia: A Communitybased cross sectional study. BMC Pregnancy Childbirth, 2016. 16: p. 149.

[24] Abota, T. L. and N. T. Atenafu, Postnatal Care Utilization and Associated Factors among Married Women in Benchi-Maji Zone, Southwest Ethiopia: A Community Based CrossSectional Study. Ethiop J Health Sci, 2018. 28 (3): p. 267-276.

[25] Belachew, T., A. Taye, and T. Belachew, Postnatal Care Service Utilization and Associated Factors among Mothers in Lemo Woreda, Ethiopi. Journal of Women's Health Car, 2016. 5 (3).

[26] Yarinbab, T. E. and W. C. Tona, Postnatal Care Utilization and Its Determinants in Loma District, Southwest Ethiopia: A Community Based Cross Sectional Study. Women's Health and Gynecology, 2018. 5 (103): p. 1-8.

[27] Kumari, S., Post natal care utilization and associated factors among women of reproductive age group. The Journal of Nursing Trendz, 2017. 8 (1): p. 7-11.

[28] Adhikari, R., Effect of Women's autonomy on maternal health service utilization in Nepal: a cross sectional study. BMC Womens Health, 2016. 16: p. 26.

[29] Teklehaymanot, A., D. Niguse, and A. Tesfay, Early Postnatal Care Service Utilization and Associated Factors among Mothers Who Gave Birth in the Last 12 Months in Aseko District, Arsi Zone, South East Ethiopia, 2016. Women's Health Care, 2017. 6 (1). 